\title{
ORIGINAL PAPER \\ Yi (Optimal Appropriateness) and Li (Benefit) in the Mengzi: Against the Consequentialist Interpretation
}

\author{
Xiangnong $\mathrm{Hu}^{1}$
}

Received: 17 May 2021 / Revised: 5 October 2021 / Accepted: 16 November 2021 /

Published online: 3 February 2022

(c) The Author(s), under exclusive licence to Springer Nature Switzerland AG 2022, corrected publication 2022

\begin{abstract}
In the opening passage of the Mengzi, Mengzi brings up the problem of the relationship between $y i$ (optimal appropriateness) and $l i$ (benefit/profit). According to a traditional interpretation, Mengzi believes that although an action from yi can sometimes produce $l i, l i$ can never be taken as the reason for deciding to act from $y i$. On the other hand, according to a more recently developed consequentialist interpretation, Mengzi suggests that we should act from yi precisely because this is actually more effective in producing $l i$ than acting with the intention of $l i$. This essay aims to argue against the consequentialist interpretation while reinforcing the traditional one. First, it demonstrates that Mengzi not only believes that $y i$ has the intrinsic moral value that makes it irreducible to $l i$ but also disapproves of the way of moral reasoning underlying the kind of consequentialism that some scholars have attributed to him. After this, the essay re-examines the traditional interpretation in the context of the characteristic Mengzian moral cultivation by taking $y i$ as a developing virtue that designates the transformative character trait of an agent, through which some previously unattended difficulties faced by the traditional interpretation will be solved.
\end{abstract}

Keywords Mengzi (Mencius) $\cdot \mathrm{Yi}$ (optimal appropriateness/righteousness) $\cdot \mathrm{Li}$ (benefit/profit) $\cdot$ Moral cultivation $\cdot$ Consequentialism $\cdot$ Virtue

\section{Introduction}

In a letter to his mentor, Zhu Xi 朱喜 (1130-1200)—one of the most influential NeoConfucian philosophers-states that "the doctrines on $y i$ 義 (optimal appropriateness) and $l i$ 利 (benefit/profit) constitute the very first principle of the Confucians” (Zhu, 2002,

Xiangnong $\mathrm{Hu}$

herbertxhu@link.cuhk.edu.hk

1 Department of Philosophy, 4/F Fung King Hey Building, The Chinese University of Hong Kong, Shatin, New Territories, Hong Kong 
vol. 21,1082$),{ }^{1}$ highlighting the significance of the issue concerning what the proper relationship should be between $y i$ and $l i$ in the study of Confucian philosophy. In order to better understand this issue and provide an adequate response, it is necessary to turn to the Mengzi, in which the problem is elucidated in detail, and for which reason the book is heavily relied on by many later Confucians when discussing the problem.

The problem is brought up in the opening passage of the Mengzi, where King Hui of Liang 梁惠王 asks Mengzi (Mencius) 孟子 (ca. 372-289 BC): “You must surely have some way of [benefitting] my state?" To which Mengzi responds: "What is the point of mentioning the word '[benefit]'? All that matters is that there should be [ren 仁 (humaneness)] and [yi]" (Mengzi 1A1). It is not difficult to see that Mengzi values $y i$ (as well as ren) more than $l i$, but what exactly is the implication of such an attitude? Does it mean, according to a traditional account, that we should embrace the yi that has intrinsic moral value and stay alert to the $l i$ that can corrupt morality? Or does it mean, according to a more recently developed consequentialist interpretation, that we should act upon $y i$ because this will actually be more beneficial than acting upon $l i$ ?

In this essay, I intend to argue against the consequentialist interpretation and reinforce the traditional interpretation by placing and examining the $y i$-li relationship in the context of Mengzian moral cultivation. I will begin by providing an overview of the consequentialist interpretation (Sect. 2), followed by a demonstration of how this interpretation, together with the consequentialist way of moral reasoning, is inconsistent with a number of passages of the Mengzi, thus rendering it less adequate than the traditional interpretation (Sect. 3). Then, I will identify and address some unresolved difficulties faced by the traditional interpretation, which are related to the problem of why Mengzi apparently uses the li generated by $y i$ to justify a moral action, by examining the yi-li relationship in the context of the distinctive Mengzian moral cultivation that takes $y i$ as a developing virtue designating the transformative character trait of an agent (Sect. 4). The essay will end with a conclusion (Sect. 5).

\section{The Consequentialist Interpretation}

Before analyzing the consequentialist interpretation, let us first clarify what characteristics an ethical theory needs to have in order to be classified as consequentialism and whether Mengzi is aware of such a theoretical framework when he discusses $y i$ and $l i$. Manyul Im, who offers the consequentialist interpretation of $y i$-li that we will examine shortly, follows William Frankena (1908-1994) and rightly points out that consequentialism is generally characterized as a kind of teleological theory, suggesting that "what makes something right—an act, rule, institution, etc.—depends ultimately on its resulting either directly or indirectly in the best outcome available, where the outcome is given in terms of the net nonmoral good that results from the act" (Im, 2011, 43). In general, no matter whether the consequentialism is an act-consequentialism that focuses on evaluating the outcomes of different actions in a given situation or a rule-consequentialism that is concerned with finding the practical rules that will promote the best outcome, the defining feature of all forms

\footnotetext{
1 The translations of the Analects and Mengzi in this article are based on those of D. C. Lau (19212010) $(1979,2003)$. For the rest of the Chinese texts, the translations are my own.
} 
of consequentialism is that "the rightness of acts, rules, or whatever is held to be dependent on the production of nonmoral good" (Im, 2011, 43).

Apparently, Mengzi does not use "consequentialism" to name any of the ethical views he addresses, but this does not mean Mengzi is unaware of or does not care about the kind of theory that we regard as consequentialism today. According to the classical commentary of Zhao Qi 趙岐 (ca. 108-201), the $l i$ that King Hui has in mind in 1A1 refers to the nonmoral good of "enriching the state and strengthening the army" (fuguo qiangbing 富國強兵) (Zhao \& Sun, 1999, 2). Moreover, if we consult the other passages, it will also not be difficult to discover that the various $l i$ that King Hui wants to attain are all nonmoral in nature. These include the enjoyment of a luxurious royal park (Mengzi 1A2), the increase in the population of his kingdom (Mengzi 1A3), and the military victory that can help him to reclaim his lost territory (Mengzi 1A5). Therefore, by asking Mengzi whether the latter has some way of benefitting his kingdom, King Hui is expecting, just like a consequentialist would expect, Mengzi to tell him which actions or rules can produce $l i$ as nonmoral good and thus are right for him to take or follow in his current situation. In other words, as Bryan Van Norden says, King Hui is acting like a consequentialist who is "being guided by [li], 'profit' or 'benefit"' (Van Norden, 2007, 303); he is prepared not only to take $l i$ into consideration during the decision-making procedure but also to justify an action or a maxim (suggested by Mengzi) by appealing to whether it can result in the production of li qua nonmoral good.

Since King Hui's view bears the defining feature of consequentialism, we can say that Mengzi's argument is directed toward the theory that we call "consequentialism" today when he persuades the king to act from $y i$ instead of $l i$. To borrow Im's words, although "the ethical views typically considered consequentialist developed and exist" in an intellectual context "far removed historically and culturally" from that of Mengzi, the "patterns of concern" expressed in his discussion with King Hui indicate that Mengzi is not unaware of an ethical view, whatever it was called at his time, that is essentially consequentialist (Im, 2011, 42). However, the question remains whether in urging King Hui to act from yi, Mengzi himself also proposes a variation of consequentialism that is different from King Hui's one in terms of its decision-making procedure but still appeals to the overall nonmoral value of the consequence for moral justification.

Some scholars in recent years have provided a positive answer to this question. ${ }^{2}$ Cai Xinan 蔡信安, for instance, points out that in 1A1, Mengzi persuades King Hui

\footnotetext{
${ }^{2}$ Apart from the two articles discussed in this essay, another important work that brings Confucianism and consequentialism together is the one by Philip Ivanhoe, who defines early Confucian ethics as a unique "character consequentialism" that is different from all other sorts of existing consequentialist theories (Ivanhoe, 1991). However, I will leave Ivanhoe's work aside for two reasons. First, Ivanhoe discusses the relationship between $l i$ and morality in the broader context of early Confucianism and not exclusively in the context of the Mengzi. Second, although we can legitimately assume what Ivanhoe's opinion would be toward Mengzi's theory of yi-li given his general theoretical framework of character consequentialism, this throws up some other questions, such as what exactly character consequentialism is and how it is different from other forms of consequentialism after all. For instance, Im argues that Ivanhoe actually fails to distinguish character consequentialism from standard act-consequentialism, and all the key elements of character consequentialism are encompassed by the "objective act-consequentialism" that Im himself assigns to Mengzi (Im, 2011, 57-60). If this were to be the case, then the objections to Im I will raise in the next section could be equally applied to Ivanhoe, but is this really the case? It appears to me that Ivanhoe's argument requires a separate treatment, so I will keep it aside for now in order to avoid distractions.
} 
to focus on $y i$ rather than $l i$ because he believes that if the king acts with the intention of $l i$, then everyone in the kingdom will imitate him by pursuing their respective $l i$ at whatever cost, and eventually "there will be no satisfaction short of total usurpation" (Mengzi 1A1). In this sense, acting from $l i$ will turn out to be counterproductive to the goal of attaining $l i$, whereas if the king could act from $y i$ and became a moral exemplar to his people, then everyone's $l i$ would be secured since "no [man of ren] ever abandons his parents, and no [man of yi] ever puts his lord last" (Mengzi 1A1). According to Cai, this suggests that Mengzi is also a consequentialist who relies on the “principle of maximal benefit" (zuida xiaoyi yuanze 最大效㿽原則)—choose the action that can maximize $l i$ - to justify a $y i$-driven action (Cai, 1987, 139).

Im understands $1 \mathrm{~A} 1$ in a similar way and further identifies some other passages that reflect Mengzi's consequentialist way of thinking (Im, 2011, 53-55). In 1A5, Mengzi again tells King Hui that if he could govern the state out of ren-yi by "[reducing] punishment and taxation, [getting] the people to plough deeply and weed promptly," this would be more effective in helping him become a powerful king than simply acting from $l i$ in terms of plundering the people with high taxation and taking them away from their work during busy seasons. In 1A7, Mengzi recommends that King Xuan of Qi 齊宣王 should extend his heart-mind of unbearableness to his people and practice ren-yi in his government because this will most effectively help him to realize his "great desire" (dayu 大欲) of uniting the various kingdoms under his rule. Furthermore, in 6B4, Mengzi once again asks what the point is of “mentioning the word "benefit"” after hearing that Song Keng 宋牼 wants to end a war by explaining to the rulers of both sides the unprofitability of the war. Similar to 1A1, Mengzi suspects Song Keng's strategy because if Song persuades the rulers by $l i$, this will lead the rulers, their soldiers, and eventually everyone in their states to be drawn to $l i$, in which case "the king of such a state is sure to perish." On the other hand, if Song could persuade the rulers by ren-yi, "then it would mean that in their mutual relations, king and subject, father and son, elder brother and younger brother, all cherished morality to the exclusion of [benefit]. The king of such a state is sure to become a true king" (Mengzi 6B4). Im concludes that all these passages suggest that "[Mengzi] considers the consequences of acting for the sake of benefit to be counterproductive of the goal of attaining benefit, and that is the reason not to act with that motive" (Im, 2011, 53). In other words, "[Mengzi's] objection to acting for the sake of benefit is that it produces bad consequences," and his recommendation to act from $y i$ is because "doing so brings about good consequences" (Im, 2011, 54).

Cai and Im then illustrate how Mengzi's consequentialism is different from the one adopted by people like King Hui. Cai argues that Mengzi's consequentialism can be regarded as a kind of "sophisticated act-consequentialism" (jingqiao de xingdong gongli zhuyi 精巧的行動功利主義) (Cai, 1987, 137). Although Cai does not explicitly explain what he means by "sophisticated," which implies that Mengzi's act-consequentialism is different from act-consequentialism in its standard form, given what he says, it would not be unreasonable to infer that Cai attributes to Mengzi an act-consequentialism that only provides "an account of 
right-making characteristics" (Bales, 1971, 262) but "the account itself places no a priori restrictions whatever on the [decision-making] procedures" (Bales, 1971, 263). In this regard, Cai indicates that Mengzi, like all other consequentialists, believes the rightness of an action to be entirely determined by the nonmoral value of its consequence (li) (Cai, 1987, 160), but unlike the other consequentialists, this does not prevent Mengzi from choosing decision-making procedures other than directly estimating and comparing the probable $l i$ of alternative actions (Cai, 1987, 168-169).

Im further articulates this point in the context of contemporary normative ethics. He borrows Peter Railton's terms and argues that Mengzi can be classified as an "objective act-consequentialist" whose view "only gives its account of right action as a criterion of the rightness of an act," which is different from a "subjective consequentialist" advocating that "the overall good to be promoted is given in the theory as the object one should consciously take in deciding what to do" (Im, 2011, 49). ${ }^{3}$ That is, according to Im, Mengzi qua an objective actconsequentialist takes something like "maximizing the $l i$ " merely as an account of right-making characteristics that determine whether a particular action is right but does not always consciously take it into account during decision-making since, as demonstrated by the aforementioned passages, directly aiming at and evaluating $l i$ will not lead to the best course of action. For this reason, Im argues, Mengzi sometimes suggests that we "focus our actions on character formation," i.e., on ren or $y i$ as a character trait, "if that were in fact more effective overall for producing good consequences. To act in such a way as to cause our characters to become effective in producing good consequences would be the right thing to do on an objective act-consequentialist view" (Im, 2011, 58), since no matter what the things that one takes into account are during decision-making, the rightness of the action still ultimately depends on "the goods to be gained or lost as a result" (Im, 2011, 59).

\section{The Problems of the Consequentialist Interpretation}

As far as I am concerned, this consequentialist or, more specifically, objective act-consequentialist interpretation of Mengzi's yi-li relationship has the unique advantage of being immune to two possible kinds of criticisms: (1) To those who may employ the passages in which $y i$ and $l i$ are directly contrasted to argue that $y i$ and $l i$ are irreducible to each other, this consequentialist interpretation can defend itself by suggesting that the irreducibility does not refer to $y i$ and $l i$ per se but to people's motives that are driven by either $y i$ or $l i$. For example, in regard to Mengzi's statement that one who gets up for $y i$ or shan 善 (goodness) is the

\footnotetext{
$\overline{3}$ For Railton's original discussion on these two kinds of consequentialism, see Railton, 1984, 152-153.
} 
same kind of person as the sage king Shun 舜, while one who gets up for $l i$ is the same kind of person as the robber Zhi 蹠 (Mengzi 7A25), the consequentialist interpretation could argue that Mengzi is not suggesting that $y i$ is irreducible to or incompatible with $l i$; rather, it means that one should indeed act completely from $y i$ instead of $l i$, but the reason for this is still that acting from $y i$ is eventually more effective in securing $l i$ than acting from $l i$ itself. (2) To the challenge: If Mengzi really held a consequentialist view, then how would he refute Mozi 墨 子 (ca. 468-376 BC) or the Mohists-Mengzi's major philosophical opponents who are generally regarded as consequentialists not only by contemporary scholars (J. Huang, 1991, 125-133; Shun, 1997, 29-35; Van Norden, 2007, 139-161) but also by Mengzi himself (Mengzi 7A26)? The consequentialist interpretation could well respond that "the difference between [the Mohists] and [Mengzi] lies not in [Mengzi] being a non-consequentialist"; rather, "[Mengzi] is critical of the Mohists because following their teachings, as [Mengzi] construes them, is unlikely to result in the best consequences" (Im, 2011, 42). In other words, Mengzi qua an objective act-consequentialist agrees with the Mohists that one's action ought to bring about the best consequences in terms of $l i$ but only disapproves of the Mohist-subjective consequentialist strategy that aims to achieve this goal by means of acting "from considerations of producing a net overall gain of benefit" (Im, 2011, 42).

Even so, one still cannot claim from here that the consequentialist interpretation is adequate. Let us start by looking at some classical commentaries of 1A1. Zhao Qi suggests that Mengzi's query regarding what the point is "of mentioning the word 'benefit", implies that, for Mengzi, ren-yi can also be used to designate the $l i$ that King Hui wants because it can bring about these $l i$ without facing the danger associated with mentioning the notion of $l i$ (Zhao \& Sun, 1999, 2). Similarly, Zhu Xi argues that what Mengzi means is that "by following the Heavenly Principle [ren-yi], then it will never be unbeneficial even without seeking the benefit; by surrendering to human's desire [li], then harm will come before the benefit is obtained" (Zhu, 2011, 188). According to Huang Zongxi 黃 宗羲 (1610-1695), passage 1A1 speaks of the “gongyong 功用” (function) of ren-yi: "It is not to say that ren and yi cannot produce benefit" (Huang, 2005, vol. 1, 49).

At first sight, these commentaries seem to support the consequentialist interpretation, but the crucial point is that they merely highlight the basic fact that an action driven by $y i$ can cause $l i$ to arise as its natural consequence, which does not in itself indicate that this is what makes the action from $y i$ right and thus serves as the reason for acting from yi. As mentioned above, in order to classify a theory as consequentialism (no matter which kind), the theory must hold that what makes something right depends ultimately on the $l i$ as the nonmoral good that results from it, but what Mengzi says in $1 \mathrm{~A} 1$ and the other passages Cai and Im used to support their interpretation does not preclude $y i$ from having an intrinsic value that is morally more important than its instrumental value of producing $l i$ beforehand-morally more important in the sense that it is this intrinsic rather than instrumental value that ultimately justifies an action from $y i$. This is consistent with what Li Minghui 李明輝 suggests: “It is one thing 
to admit that ' $y i$ ' can produce ' $l i$ '; while it is another thing to take the resulting ' $l i$ ' as ' $y i$ '" (Li, 2018, 189); whether Mengzi is a consequentialist and whether $y i$ is reducible to $l i$ depend on whether $y i$ has its own intrinsic moral value that should be upheld as an end in itself. ${ }^{4}$ If it has, then the consequentialist interpretation will not work.

One of the passages revealing that $y i$ has intrinsic moral value is 7A21. Here, Mengzi distinguishes what a junzi 君子 (morally exemplary person) "sиoуu 所 欲” (desires), “suole 所樂” (delights in), and “suoxing 所性” (follows as their nature): "An extensive territory and a huge population are things a [junzi] desires"; "to stand in the center of the Empire and bring peace to the people within the Four Seas is what a [junzi] delights in"; and ren, yi, li 禮 (observance of rites), and zhi 智 (wisdom) are "what a [junzi] follows as [their] nature." According to Zhao Qi, the object of suoyu refers to being "a lord of a great state," and the object of suole refers to being "a true king" (Zhao \& Sun, 1999, 362). These, as we have seen, are the $l i$ that common rulers such as King Hui and King Xuan want to attain, which can be effectively produced by $y i$. Nevertheless, despite $y i$ being able to produce these $l i$, Mengzi says in this passage that the true value of $y i$, as a part of that which a junzi takes as their morally good nature, "lies elsewhere" (Mengzi 7A21). This points to the existence of the intrinsic moral value of $y i$ that stands independently of any $l i$, which is affirmed by Mengzi as "[the value of $y i]$ is not added to when the [junzi] holds sway over the Empire, nor is it detracted from when [s/he] is reduced to straitened circumstances"; it is bestowed by Heaven and rooted in the junzi's heart-mind, the manifestation of which alone can give the junzi a morally magnificent appearance (Mengzi 7A21).

This intrinsic moral value of $y i$ has also been demonstrated in 2A6 and 6A6. In both passages, Mengzi claims that all human beings are natively endowed with the "sprouts" (duan 端) of ren, yi, li (observance of rites), and zhi, which can

\footnotetext{
${ }^{4} \mathrm{Im}$ acknowledges that $y i$ has intrinsic moral value, but what he means by this is something different. For Im, yi's intrinsic moral value lies in its being an "esteem-based moral good," which is an object of "moral admiration or esteem" that a consequentialist theory can incorporate within its basket of goods (Im, 2011, 47-48). In general, this account has at least three problems: (1) Im says that moral esteem is "perhaps a species of desire" that has "a psychological 'shape' to it that distinguishes it from other species of desire broadly construed," but he does not explain what exactly this ambiguous "psychological shape" is (Im, 2011, 47). This makes the distinction between moral desire/esteem and nonmoral desire especially difficult, which in turn makes it equally difficult to determine what $y i$ is as the object of such a moral desire. (2) Im seems to believe that $y i$, as the moral good, will not run into conflict with $l i$, as the nonmoral good, but in several places, Mengzi shows that $y i$ sometimes needs to be possessed at the great cost of abandoning li (Mengzi 6A10, 6A17, 7B34, 7B35). In these cases, why would Mengzi encourage people to give up $l i$ for the sake of $y i$ as a kind of desirable esteem, especially when doing so will not necessarily produce the amount of $l i$ that can compensate one's loss? (3) The passages I will discuss in the following show that Mengzi praises an action from yi not because it fulfills the desire for admiration or esteem, which suggests that the fulfillment of this kind of desire is not part of the intrinsic moral value of $y i$. On the other hand, $y i$ 's intrinsic moral value in my context lies in $y i$ being a virtue that not only reflects the character trait of an agent but also essentially constitutes a human being's nature (xing 性) that alone distinguishes humans from non-human animals (Mengzi 2A6, 4B19, 6A6); it is not reducible to an object of a special kind of desire.
} 
manifest themselves in terms of the heart-mind of compassion, shame, respect, and right and wrong. ${ }^{5}$ These sprouts of ren-yi not only constitute the property that distinguishes humans from non-human brutes but are also highly regarded by Mengzi as the sufficient evidence of human being's inherent inclination toward moral goodness. Moreover, in 2A6, Mengzi also makes it clear that this intrinsic moral value of (the sprouts of) ren-yi should be taken as what can ultimately justify an action driven by them. At the beginning of the passage, Mengzi says that the former sage kings can govern the state in a compassionate and virtuous way and thus can easily "rule the Empire as rolling it on [their] palm," but the reason for their compassionate government is not this good consequence that results from it. Rather, "the former sage kings have the heart-mind sensitive to the suffering of others, so [emphasis added] they have government that is not insensitive to the suffering of others" 6 - if the former sage kings were asked to justify their compassionate government, they would appeal to its motivating force, i.e., ren-yi manifested as the heart-mind of compassion, ${ }^{7}$ rather than the $l i$ of its consequence.

Then, Mengzi illustrates a scenario in which someone suddenly sees a young child on the verge of falling into a well:

One would certainly be moved by the heart-mind of compassion, not because one wanted to get in the good graces of the child's parents, nor because one wished to win the praise of his fellow villagers or friends, nor yet because one disliked the cry of the child (Mengzi 2A6).

At this point, Mengzi merely suggests that the emergence of the heartmind of compassion qua the sprout of ren is irrelevant to the various $l i$ of saving the child, but based on the context, we can legitimately infer that Mengzi would also encourage and expect people to, as Jiao Xun 焦循 (1763-1820) and Zhu Xi have phrased, "set this heart-mind into practice" (Jiao, 2017, 194) or "act in response to it" (Zhu, 2011, 220) without taking the $l i$ associated with saving the child into consideration at any stage of the

\footnotetext{
5 The notion "sprout" does not appear in 6A6, but I have argued in another paper that this does not make the ren, yi, li, and zhi in 6A6 substantially different from the sprouts of them in 2A6; in both passages, Mengzi refers to the "relatively antecedent" and immature ren, yi, li, and zhi (Hu, 2021).

6 The translation of this sentence is my own. The original Chinese reads: 先王有不忍人之心, 斯有不忍 人之政矣. Van Norden provides a similar translation (Van Norden, 2008, 46).

7 Despite all having intrinsic moral value and being called the heart-mind of compassion, the former sage kings' heart-mind of compassion, as the result of a long-term moral cultivation, is qualitatively different from ordinary people's heart-mind of compassion, as an immediate reaction to certain events, for Mengzi says that the former can be employed to "tend the whole realm within the Four Seas," whereas the latter "will not be able even to [properly] serve one's parents" (Mengzi 2A6). Therefore, it would be more accurate to say that the former sage kings' heart-mind of compassion is the manifestation of fully developed ren-yi rather than mere sprouts of ren-yi. This also suggests that the sprouts of ren-yi are not as morally reliable as fully developed ren-yi; people who merely possess the sprouts will lack the ability to always act properly under different circumstances. This is why Mengzi urges people to fully develop the sprouts through moral cultivation. I have discussed this point in detail in the other paper (Hu, 2021) and will also address it in the next section.
} 
action. ${ }^{8}$ For not only does Mengzi emphasize that humans share the sprouts of ren-yi that would potentially allow them to act in the same way as the former sage kings, but he also explicitly criticizes those who deny this- "for a man possessing these four sprouts to his potentialities is for them to cripple himself; for him to deny the potentialities of his prince is for him to cripple his prince" (Mengzi 2A6)-indicating that people ought to develop the sprouts and be able to act in the same way as the former sage kings, who will not rely on $l i$ to justify their moral actions driven by ren-yi.

Another defense for the last point can be drawn from 3B1, in which Mengzi opposes Chen Dai's 陳代 suggestion of "bending the foot in order to straighten the yard," meaning to persuade Mengzi to compromise himself in order to get the opportunity of meeting and rectifying a ruler (Zhao \& Sun, 1999, 159; Zhu, 2011, 246). Now, it may appear that the objective act-consequentialist interpretation can construe this passage in much the same way as 1A1 because Mengzi's reasoning here is again that a person who will act in accordance with Chen Dai's suggestion is a person who acts from $l i$; such a person will do whatever they find necessary in order to secure the $l i$ and eventually, even if they could meet a ruler, they would fail to make them become great and virtuous since "there has never been a [person] who could straighten others by bending [oneself]" (Mengzi 3B1). Therefore, one should not directly aim at $l i$ during decision-making as doing so is counterproductive.

So far so good, but an important difference between passages such as 1A1 and 3B1 exists at this point. In the first case, in addition to pointing out the unprofitability of acting from $l i$, Mengzi also assures people like King Hui that $l i$ will come out of acting from $y i$, whereas in the second case, Mengzi uses a few analogies to demonstrate that one should act appropriately without bending the foot, i.e., act from $y i$, even if this will be unprofitable rather than profitable. This suggests that, for 3B1, although the consequentialist interpretation could explain why $l i$ should not be taken into consideration during decision-making, it could not explain why the promotion of $l i$ is not used in this case as the ultimate criterion of the rightness of action. Mengzi directly tells us that in the short run, acting from $y i$ may bring death or cause one to earn nothing (Mengzi 3B1). In the long run, although one could assume, for example, that acting from $y i$ would gain the person a good reputation, which would in turn result in the person being invited to court and assisting the ruler more easily, given the corruptness of those rulers portrayed in the Mengzi, I believe it would be more likely, or at least equally likely, that the virtuous person would be disliked and left ignored, and the corrupted rulers would simply remain corrupt. ${ }^{9}$ In either case, $l i$ is not guaranteed when one acts from $y i$, but Mengzi still refuses Chen Dai's suggestion without any hesitation. Based on what has just been discussed, the reason must be that an action from $y i$ has an

\footnotetext{
${ }^{8}$ Recall that the consequentialist interpretation agrees that $l i$ should not be considered during decisionmaking, but it argues that Mengzi nevertheless uses $l i$ as the "criterion of the rightness of an act." This passage (as well as the next) shows that Mengzi believes that people should take $l i$ into consideration neither during decision-making nor at the stage of justification. Furthermore, I will argue shortly that Mengzi also opposes the objective act-consequentialist way of moral reasoning.

${ }^{9}$ Mengzi himself was forced to leave King Xuan's court and remained unappreciated (Mengzi 2B10-14).
} 
intrinsic moral value that trumps all the nonmoral values $(l i)$ it can produce, which should be upheld as an end in itself.

These passages are certainly not meant to be exhaustive, but I hope they are sufficient for the purpose of revealing the moral significance of $y i$. Leaving this point aside, we can also refute the consequentialist interpretation indirectly by appealing to the way of moral reasoning underlying the objective act-consequentialism, which suggests something like this: in order to achieve goal $G$, do not act directly from $G$ but from non- $G$, given that this non- $G$ can be justified by promoting $G$. Such reasoning is also criticized by Mengzi in his correspondence with the Mohist Yizi 夷子 in 3A5, which suggests that Mengzi is very unlikely to adopt the same view himself and analyze the relationship between $y i$ and $l i$ accordingly.

In 3A5, after hearing that Yizi gave his parents lavish burials, Mengzi doubts whether it is appropriate for Yizi to do this as a Mohist because "in funerals, the Mohists follow the way of frugality. Since Yizi wishes to convert the whole Empire to frugality, it must be because he takes it as the only honorable way [that should be practiced universally]" and should not therefore treat his parents in an exceptional manner. Then, in responding to this criticism, Yizi says: "The Confucians praised the ancient rulers for acting 'as if they were tending a newborn babe.' What does this saying mean? In my opinion, it means that there should be no gradations in love, though the practice of it begins with one's parents."

This response seems to be irrelevant to Mengzi's criticism, but its meaning will become clearer if we understand what is truly implied by Mengzi's criticism. As Zhu Xi comments, Mengzi's criticism is primarily concerned not with the Mohist teaching of frugal burials but with the overarching Mohist principle of "no gradations in love" (ai wu chadeng 愛無差等), for what Mengzi indicates is that Yizi does not follow the Mohist way of burials because he has more concern for his parents, which naturally causes him to feel unsettled if he practices "no gradations in love" by giving his parents and strangers frugal burials alike (Zhu, 2011, 244). Yizi must be well aware of this, so instead of defending the Mohist way of burials or denying his greater affection for his parents, he tries to justify his feeling and behavior by appealing to their compatibility with the principle of "no gradations in love"-even the Confucian sage kings believe that, ultimately, there should be no gradations in love. However, given the limitation of human capacities, the practice of this love has to begin with one's parents and then gradually be extended to others. That is to say, giving one's parents lavish burials out of love is totally justifiable as long as it can provide the basis for one to learn to love and treat everyone in the same way. ${ }^{10}$

Noticeably, as Van Norden has also pointed out (Van Norden, 2007, 306), Yizi's reasoning is highly objective act-consequentialist in nature, for he does not act

\footnotetext{
${ }^{10}$ In regard to the meaning of Yizi's response, Huang Zongxi and Van Norden suggest a similar interpretation (Huang 2005, vol. 1, 82; Van Norden, 2007, 306), but Zhu Xi and David Nivison (1923-2014) offer two alternatives (Nivison 1980, 739-742; Zhu 1986, vol. 3, 1313). In general, Zhu believes that Yizi makes a self-contradictory "subterfuge" (dunci 遁詞) by claiming that he acts directly from "no gradations in love" but still has to start practicing this impartial love with his parents; and Nivison argues that Yizi tries to defend himself by admitting and appealing to his ethical immaturity. Both of them, I believe, commit the same problem of uncharitably rendering Yizi's argument particularly weak and undeserving of Mengzi's serious criticism as Van Norden has identified (Van Norden, 2007, 307).
} 
directly from "no gradations in love" (as the ultimate goal to be achieved) when he implicitly admits that he acts out of his particular love toward his parents, but nonetheless "no gradations in love" still serves as the "account of right-making characteristics" that can be used to determine whether the action is justifiable-apparently, if the action can help promoting impartial love, then it will be considered as right. To such an argument, Mengzi responds:

Does [Yizi] truly believe...that a man loves his brother's son no more than his neighbor's newborn baby? He is singling out a special feature in a certain case: when the newborn baby creeps toward a well it is not its fault. Moreover, when Heaven produces things, it gives them a single basis, yet [Yizi] tries to give them a dual one. This accounts for his belief (Mengzi 3A5).

What does this mean? Basically, as Van Norden suggests, by asking the first question, Mengzi intends to draw our attention to the facts that "(1) people almost invariably do care more for relatives than for strangers, and (2) most people share the ethical intuition that we ought to have such differential ethical concern" (Van Norden, 2007, 308). Those like Yizi who deny these facts place too much attention on the exceptional case illustrated in 2A6 while neglecting that, in most circumstances, even sages and junzi treat their relatives differently from strangers, indicating that it is right to do so (Mengzi 5A2, 5A3, 7A26, 7A35). Hence, the natural inclination toward one's relatives that is inherent in one's heart-mind should be the only "one basis" (yiben 一本) bestowed by Heaven for both practical decision-making and justification; it would be mistaken to introduce another principle- "no gradations in love" in Yizi's case — as another basis and thus rely on a "dual basis" (erben 二本), one for decision-making and one for justification, in moral reasoning.

I agree with Van Norden that Mengzi's criticism of Yizi resembles the one Michael Stocker raises against contemporary act-consequentialism (Van Norden, 2007, 310), which blames its way of moral reasoning for producing a kind of "moral schizophrenia"_- “a split between one's motives and one's reasons" (Stocker, 1995, 531). In the case of Yizi, one's natural inclination toward one's parents, which is the innate motivation playing the key role in decision-making, is not directly connected to the justification of the action, as the latter ultimately depends on its efficacy in promoting "no gradations in love," thus rendering anyone who follows such a doctrine morally disjointed, if not schizophrenic. Consequently, given the nature of Mengzi's criticism, it would be unimaginable for Mengzi himself to adopt a theory such as objective act-consequentialism that would inevitably commit him to dealing with $y i$ and $l i$ by adhering to this disjointed way of thinking, i.e., by taking $y i$ as motivation while appealing to $l i$ for justification.

\section{Rethinking the Yi-Li Relationship in the Context of Mengzian Moral Cultivation}

Given these problems with the consequentialist interpretation, it becomes reasonable at this point to see if we can better understand the yi-li relationship by turning back to the traditional interpretation, which in general suggests: 
When sages do things, they only do toward the side of $y i$. However, $y i$ is not unbeneficial, but benefit cannot be spoken at first; the heart-mind of seeking benefit cannot be possessed at first. This is because the Way originally only contains one idea of ren and $y i$ and has nothing else.... Sages ask people only to follow one road to do things; do not work on this side while also considering about the other side (Zhu, 1986, vol. 3, 1218-1219).

This account should appear to be much more plausible than the consequentialist one as it accurately reflects the facts that (1) despite an action from $y i$ being able to have the instrumental value of producing $l i$, this should not be used as the reason for deciding to act from $y i$; rather, an action from $y i$ is right in itself and should be practiced for its own sake; and (2) in moral reasoning, one should only take $y i$ but never take both $y i$ and $l i$ into consideration. ${ }^{11}$ Nonetheless, I think this traditional interpretation still faces some difficulties in explaining the passages that Cai and Im used to support their interpretation in Section Two.

After consulting the general context of the Mengzi, we know that Mengzi himself knows very well that $y i$ has intrinsic moral value and should not be practiced merely for the sake of gaining $l i$, but the question is whether the people, such as King Hui and King Xuan, who talk with Mengzi in those passages also realize this truth. Leaving aside all the possibilities that cannot be proved by the text, I think it is most likely that they do not or do not entirely realize it, for they are morally unequipped, and their conversations with Mengzi just end with Mengzi telling them the $l i$ of acting from $y i$. In this case, suppose King Hui successfully acted from $y i$ and did what Mengzi suggests him to do on an occasion and was then asked to justify his action, we could easily imagine that he would just say: "Because Mengzi once told me that doing this will more effectively produce the li I want"- -this is a morally disjointed, objective act-consequentialist answer that Mengzi will not tolerate. However, it seems that Mengzi himself is responsible for this after all, for it is he who initially instilled this way of moral reasoning into the king's mind when the latter was told nothing more than the instrumental

\footnotetext{
11 These basic ideas have been phrased in various ways by many contemporary scholars, see Chen 1987, 297-300; J. Huang 1991, 133-139; Li 2018, 188-190; Wang 2017, 27-30; Yang 1996, 106; Ye 2011, 22-28, among others. In addition, two points need to be noted: (1) Some of these scholars draw a distinction between sili 私利 (private profit) and gongli 公利 (public profit) and argue that Mengzi opposes the former and only accepts the latter as the natural consequences of yi (J. Huang 1991, 133; Wang 2017, 30). This distinction is problematic but has been sufficiently addressed (Chen 1987, 282-285; Li 2018, 155-158), which does not require further discussion here. (2) The traditional interpretation presented here is referred to by Ye Renchang 葉仁昌 as the model of "producing li by following yi" (yiyi sheng li 以義生利), and Ye further distinguishes between two different variations of it: the model of "resisting $l i$ by following yi" (yiyi chi li 以義斥利) and “prioritizing yi over li" (xianyi houli 先義后利) (Ye 2011, 3). In short, the former suggests that Mengzi resists any kind of $l i$ for the sake of preserving $y i$, and the latter suggests that $y i$ should be taken as a premise, but $l i$ still needs to be intentionally sought under this premise. From the discussions made in the previous sections, I hope it is not difficult now to see that neither of these two variations is correct (Ye also discusses their problems in Ye 2011, 12-17, 29-31), so by "traditional interpretation," I only refer to its standard version presented here.
} 
function of $y i .^{12}$ Then, we may ask: Why does Mengzi persuade the king in this way if he truly believes that $y i$ should be practiced for its own sake? Moreover, if it were ever possible, how would Mengzi manage the risk of making his recipients morally disjointed?

In order to solve these problems, let us start by considering what yi is for Mengzi. Although Mengzi believes that $y i$ has intrinsic moral value, this does not automatically turn it into, as some have suggested (Li, 2018; Yang, 1996, 103; Ye, 2011, 28), a deontological principle in the same sense as a Kantian categorical imperative. This is because, as I have argued in another place, "nowhere in the book does Mengzi propose any moral substance at first, nor does his moral reasoning rely on a top-down model starting with some universal moral principles. In fact, Mengzi explicitly opposes the idea of 'holding to an inflexible oneness' (zhiyi 執一) (Mengzi 7A26)," and his emphasis is always on the diverse characters of the moral agents instead (Hu, 2021, 188). This is particularly evident in the case of ren, where we can see that the term is closely associated with various moral feelings or actions that are expressed or carried out by morally exemplary people. Some of these feelings or actions, such as the love one feels toward one's parents (Mengzi 4A27, 7A15) and not being "willing, as a morally good man, to serve a corrupted ruler" (Mengzi 6B6), are obviously different in content or even contradictory to some others, such as the grudges that sometimes arise from loving one's parents (Mengzi 5A1, 6B3) and "serve [the sage king] Tang five times and serve [the tyrant] Jie five times" (Mengzi 6B6). They are nevertheless all regarded as manifestations of ren not because they meet a common, fixed moral standard called ren but because the agents who perform them are all ren, i.e., virtuous, agents_- "All that is to be expected of a [junzi] is [ren]. Why must [s/he] be exactly the same as other [junzi]?" (Mengzi 6B6).

Given this background of Mengzian ethics, and given that $y i$ is spoken of on an equal basis with ren, it is as expected that $y i$ is also not a moral principle but is a virtue that defines a person's character. ${ }^{13}$ Further support for this point can be drawn from 4B11, where Mengzi says: "A great man need not necessarily be truthful in every word he says, nor does he necessarily see his action through to the end. He aims only at what is [optimally appropriate]." Apparently, it would be very difficult to interpret this statement if we understood this $y i$ as a Kantian categorical imperative, for intentionally lying and breaking promises, as a subjective maxim of action, cannot possibly be willed as a universal practical law; Mengzi is not ignorant to the extent of advocating that everyone, regardless of their moral capacities, can and should always break their promises whenever they subjectively and randomly find it appropriate. Rather, the subject of $4 \mathrm{~B} 11$ is a "great man" (daren zhe 大人者), which suggests that the agent must be morally mature enough in the first place in order to act in that controversial way, precisely because Mengzi believes that a great

\footnotetext{
12 Ye Renchang recognizes this as a huge trap in Mengzi's theory of $y i$-li that causes Cai Xinan to doubt the plausibility of the traditional interpretation and turn to understand Mengzi in a consequentialist way (Ye 2011, 32). Unfortunately, Ye does not fill up this trap, and so the traditional interpretation still faces the danger of being modified in this misleading manner.

13 One may recall from Section Two that Im also says that $y i$ is a character trait, but the key difference is that he does not believe it has the right kind of intrinsic moral value. See footnote 4 for details.
} 
man will be morally reliable in the sense that he knows what kinds of actions are optimally appropriate in different situations and can make sure that his actions will never be outrageous. In other words, 4B11 should be understood as a description of the moral state of a great man-what a great man looks like and what he will dobut not as illustrating how a great man acts in accordance with a moral principle; the focus is on the character trait of the agent rather than any moral law. Therefore, I think Vincent Shen (1949-2018) makes the point when he argues that, for Mengzi, $y i$ is not the $y i$ in the sense of a “duty” or “obligation” ( $y i w u$ zhi yi 義務之義) but in the sense of a “virtue" (dexing zhi yi 德行之義) (Shen, 1992, 189). ${ }^{14}$

Tang Junyi 唐君毅 (1909-1978) once suggested that the primary concern of Mengzi's teaching is to "uplift every human being's heart-mind and will, raise them from below, and set them up toward the top" (Tang, 1986, 214), which points to the fact that $y i$, as a virtue representing a human being's character trait, is open to moral development. Indeed, Mengzi believes that everyone is originally endowed with a "heart-mind of shame" (xiuwu zhi xin 差惡之心) as the sprout of yi (Mengzi 2A6, 6A6) and is naturally able to "love their parents" (jingzhang 敬長) (Mengzi 7A15), which shows that human beings are not devoid of the $y i$ that marks the "slight difference" (jixi 幾希) between humans and brutes (Mengzi 4B19). However, we have seen in 2A6 that these only represent $y i$ in its original, immature, and undeveloped form, as Mengzi also says that those who only stay with the sprouts of ren-yi "will not be able even to [properly] serve their parents" (Mengzi 2A6) and compares this kind of ren-yi to an unripe grain (Mengzi 6A19) that requires further nourishmenta process termed “extension” by Mengzi (kuochong 擴充) (Mengzi 2A6, 7B31).

This Mengzian extension or moral cultivation has two interrelated features that are relevant to our current discussion. First, it is a gradual, step-by-step process toward moral perfection, and people at different stages of this process will develop different characters and become morally capable of handling different affairs. This feature is demonstrated by the case of Yue Zhengzi 樂正子. In 7B25, Mengzi considers Yue Zhengzi as a "good man” (shanren 善人) and a "true man” (xinren 信人) and explains where Yue Zhengzi is in the process toward moral perfection:

The desirable is called "good." To have it in oneself is called "true." To possess it fully in oneself is called "beautiful," but to shine forth with this full possession is called "great." To be great and be transformed by this greatness is called "sage"; to be sage and to transcend the understanding is called "divine." [Yue Zhengzi] has something of the first two qualities but has not quite reached the last four.

\footnotetext{
14 Thus, I agree with Van Norden that Mengzi's ethics can be regarded as virtue ethics in a thin but not thick sense, which means they contain the defining elements of virtue ethics, but their thick accounts of these elements are different from, say, Aristotelian or Humean virtue ethics (Van Norden, 2007, 20-21). According to Rosalind Hursthouse, a virtue ethical theory has generally been characterized as "agentcentered" rather than "action-centered," suggesting that it takes the character trait of the agent as primary in ethics from which other concepts such as right action and moral law are derived (Hursthouse 1999, 25). This in turn requires it to offer a list of virtues and an account of moral cultivation as how one can acquire those virtues (Van Norden, 2007, 21).
} 
This evaluation of Yue Zhengzi's moral state is not a random one as Mengzi also says elsewhere that Yue Zhengzi is "a man who is drawn to the good" (Mengzi 6B13), which grants him the characters of "good" and "true" and enables him to govern a state, but sometimes he does not know how to treat his elders properly (Mengzi 4A24), showing that he has not obtained the qualities of those four stages following "true" and is yet unable to make full use of "the way of antiquity" that he has learned except for using it to earn a living (Mengzi 4A25). ${ }^{15}$

The second feature is that this moral cultivation needs to follow a natural course of development; proceeding too fast due to overeagerness or remaining stagnant due to indifference can both have detrimental effects. Mengzi uses an analogy of seedlings to illustrate this point:

You must look at $[y i]$ and never let it out of your mind. At the same time, while you must never let it out of your mind, you must not forcibly help it grow either. You must not be like the man from Song. There was a man from Song who pulled at his seedlings because he was worried about their failure to grow. Having done so..., his son rushed out to take a look and there the seedlings were, all shriveled up... There are some who leave the seedlings unattended, thinking that nothing they do will be of any use. They are the people who do not even bother to weed. There are others who help the seedlings grow. They are the people who pull at them. Not only do they fail to help them, but they do the seedlings positive harm (Mengzi 2A2).

It is true that seedlings need a farmer's care in order to grow properly, but no matter how attentive a farmer is, the growth and maturity of seedlings will be gradual and time-consuming. Under such circumstances, focusing too much on the seedlings and overeagerly giving them an excessive amount of care to increase their speed of growth will severely interfere with their natural rhythm of growth and thus be as devastating as not giving them any care at all. Similarly, in moral cultivation, "one has to edge into the [morally] desired way of life gradually" (Shun, 1997, 156); overeagerly forcing oneself or others to practice things that are still "too moral" 16 to one's character can do morality a "positive harm" in terms of, for example, making people find moral cultivation overly demanding and thus stop proceeding further, give up, retreat to the starting point, and eventually lose confidence-these can be as detrimental as or even more detrimental than refusing to start the cultivation in the first place.

One may wonder at this point whether Mengzi's argument here is consequentialist, as it seems that the reason for adopting such a way of moral cultivation is that it will bring the best outcome. In regard to this concern, the first thing we need to note is that the "best outcome" in the context of the Mengzian moral cultivation refers to

\footnotetext{
${ }^{15}$ Zhu Xi provides a similar interpretation and compares Yue Zhengzi to Yan Hui 顏回 (ca. 521-481 BC), who is supposed to be morally superior to Yue Zhengzi, which further shows that people at different stages of moral cultivation will acquire different characters and abilities (Zhu 2011, 347).

16 This highlights the connection between the second and the first feature as what can be considered as "too moral" varies across people at different stages of moral cultivation and depends ultimately on the very individual's own character and ability.
} 
the successful development of $y i$ as a virtue designating an agent's character trait, the intrinsic value of which, as shown in the last section, is not defined or calculated in terms of the $l i$, qua the nonmoral good, that results from it. We have seen that although Mengzi does not deny that $y i$ sometimes can produce $l i$, he also makes it very clear that it sometimes can result in things that no one would take as (non-morally) good and pleasant (recall what Mengzi says in 3B1, as well as 6A10). Therefore, since from a consequentialist standpoint, the Mengzian moral cultivation may not necessarily bring a nonmoral value that is overall greater than, say, taking a different method of cultivation or refusing to cultivate oneself at all, it would be very hard for Mengzi to really justify his method of cultivation by appealing to the consequentialist criterion. ${ }^{17}$

Second, and more importantly, even if Mengzi could somehow prove that, compared to all other methods of moral cultivation, his method can bring the greatest $l i$ to its practitioners, this will still not render Mengzi's argument consequentialist because, as Rosalind Hursthouse points out, "one can, as a fairly virtuous person..., be adequately motivated to perform virtuous actions for the right reasons and, as a quite separate issue, give justifying grounds for one's belief that the virtues...benefit their possessor" (Hursthouse, 1999, 180). That is, Mengzi may well believe that practicing what has been suggested by his method of moral cultivation can truly benefit people and also justify this belief when he is asked to do so, but this does not automatically suggest that, when Mengzi adopts this method, he adopts it because he believes that it will benefit people; this belief is not the reason that Mengzi will use to explain and justify his adoption of the method. On the contrary, as some commentators have noted, Mengzi indicates in 2A2 that the reason why he adopts the current method of moral cultivation is because this method has originally been demonstrated by Zengzi 曾子, one of Confucius' 孔子 (551-479 BC) direct disciples who is regarded as being very virtuous (Jiao, 2017, 161; Zhu, 2011, 214), emphasizing that this way of moral cultivation is "what a virtuous agent would characteristically (i.e., acting in character) [adopt]" and therefore is right in itself (Hursthouse, 1999, 28).

After making this point clear, given the two characteristics of the Mengzian moral cultivation, it follows that Mengzi is, in Howard Curzer's term, a "savvy sage" who is well aware that people "need different strategies of character improvement because different people are at wildly different points on the path to virtue.... Different stages of moral progress demand different strategies" (Curzer, 2020, 381). Therefore, for those wicked rulers and morally deficient people who are at the very starting point of the moral progress, Mengzi has to find a way that can make moral behavior and cultivation appear promising rather than daunting. This is why he only tells King Hui and King Xuan that $y i$ as a virtue will benefit its possessors and apparently allows them to use this as their reason for starting their moral practice but does not blatantly tell them the truth (the intrinsic moral value of $y i$ should be upheld as an end in itself) or ask them to intentionally practice something that is too demanding to their current moral state. ${ }^{18}$ To a large

\footnotetext{
17 This also shows that " $y i$ can effectively produce $l i$ " can only be used to encourage people for moral cultivation but not be taken as the ultimate truth.

18 For example, Mengzi does not directly tell King Xuan to reduce or abandon his desires for li (Mengzi $1 \mathrm{~B} 1,1 \mathrm{~B} 5)$ when in fact, "there is nothing better for nurturing of the heart-mind" than doing so (Mengzi 7B35).
} 
extent, I think Mengzi is practicing the so-called "teaching in accordance with one's characters" (yincai shijiao 因材施教) that was once demonstrated by Confucius' everchanging answers to the same question asked by his disciples with different characters (Analects 11: 22). For this way of teaching, just like what we have said in relation to Mengzi's argument for his moral cultivation, Mengzi should have believed that, when someone is so indulged in the immoral way of life for a long time, the best way to encourage them to give up that way of life and start to cultivate themselves is to let them do it with the hope that a virtue such as yi will be beneficial. Simultaneously, Mengzi should have chosen this way of teaching not only because it is required by his moral cultivation, which is right in itself and always takes the agent's current character trait and moral capability into full consideration, but also because Confucius has practiced it as a virtuous agent, if not a morally perfect sage. ${ }^{19}$

Now, we come to the second question of how Mengzi would make sure that those morally deficient people who talk with him will not use $l i$ for moral justification once they have successfully acted from $y i$ on an occasion. In general, Mengzi has at least two ways of handling this. First, Mengzi will, implicitly and mildly, guide them to stay focused on their motivation instead of the consequences of their actions when there is such an opportunity. For instance, in analyzing King Xuan's behavior of sparing an ox from a sacrificing ceremony in 1A7, Mengzi mentions in particular that commoners in the state tend to believe that the king did this for the sake of saving the expense, to which King Xuan, perhaps getting a little annoyed by his people's ignorance, responds: "[Qi] may be a small state, but I am not quite so miserly as to grudge the use of an ox. It is simply because I could not bear to see the ox shrink with fear [emphasis added]." Then, rather than immediately approving the king's justification for his action, Mengzi further explains to the king why commoners have misunderstood him, which triggers the king to emphasize again that "it is not true that I grudged the expense." Finally, the king feels pleased and enlightened after Mengzi assures him that his appeal to his motivation, i.e., the heart-mind of “unbearableness" (buren 不忍), for justification is all right and is "the way of a [ren] person" (Mengzi 1A7). We can posit that Mengzi would always encourage and expect the king to reflect in the same way whenever he acts from this heart-mind as (the sprouts of) ren-yi.

Second, to some extent, Mengzi should have had the confidence that those people will simply not be able to justify their moral actions against the $l i$ that they want. This is not only because $l i$ sometimes may not arise as a result of $y i$ but, more importantly, because "the virtuous and the immoralist are going to have distinctively different views on what counts as, for example, benefit and advantage, harm and loss" (Hursthouse, 1999, 182) — the " $l i$ " in Mengzi's statements like "an action from $y i$ will produce $l i$ " refers to the things that would be regarded as $l i$ by a virtuous person who can act from $y i$, which are unlikely to be exactly the same in content as the $l i$ that an immoralist like King Hui or King Xuan would have in mind. This means that, when an action from $y i$ does produce $l i$, it only produces the $l i$ favored by a virtuous agent rather than an immoralist, hence it would be very difficult for the latter

$\overline{{ }^{19}}$ Mengzi also says in 2A2 that "it is my hope and wish to follow the example of Confucius.". 
to use what results from a $y i$-driven action-something that they would not regard as $l i$ - to justify the action.

Let us take King Xuan as an example again. In 1B5, King Xuan says he is "fond of money" and "fond of women," which points to the $l i$ that he desires. Furthermore, he takes this fondness as the "weakness" ( $j i$ 疾) that prevents him from doing what Mengzi suggests him to do, apparently because he believes that this fondness is in conflict with Mengzi's suggestion of governing the state out of ren-yi ${ }^{20}$ in terms of placing "no levy at border stations and market places" and taking care of men without a wife-to do the former would reduce the amount of money that he can spend, while to do the latter would refrain him from taking too many women into his court. In response, Mengzi tells King Xuan that former sage kings such as Gong Liu 公劉 and Tai Wang 太王 are also fond of money and women, but the difference is that they can share this fondness with their people while enjoying these $l i$ themselves: Gong Liu ensures that "those who stayed at home had full granaries and those who went forth to war had full sacks that the march could begin," and Tai Wang ensures that "there were neither girls pining for a husband nor men without a wife" (Mengzi 1B5).

On the one hand, Mengzi intends to show to King Xuan that acting or governing in a virtuous way will not prevent him from attaining and enjoying the $l i$ he wants (money and women), as the former sage kings have shown that these $l i$ can be enjoyed while being virtuous. On the other hand, however, a point that Mengzi does not make explicit is that, if the sage kings could truly act and govern out of ren-yi by taking care of their people's same needs, they would naturally find things such as taking a great proportion of money and women into their court at the cost of preventing others from having them highly inappropriate and thus refuse to do them. In other words, although the sage kings also enjoy money and women as $l i$, these $l i$ that they would enjoy, as the natural consequences of their moral actions driven by ren-yi, will still be different in some way (perhaps in quantity or in terms of when they can enjoy them) from those that King Xuan would enjoy, as the latter would not accept a consequence that includes what must be given up for the sake of taking care of the people as li. Consequently, if King Xuan himself could act and govern his state out of $r e n-y i,{ }^{21}$ the $l i$ that he has in mind, which includes taking money and women as many as possible without caring about his people's needs, would not be realized either, so it would be extremely difficult for him to discern a connection between

\footnotetext{
20 The original term that Mengzi uses is “wangzheng 王政” (kingly government), which can only be realized by "putting [ren] into effect through the transforming influence of morality" (Mengzi 2A3) or “act from ren-yi" (you renyi xing 由仁義行) (Mengzi 4B19).

${ }^{21}$ In this case, Mengzi directly tells King Xuan what the actions and policies of former sage kings are, so it is possible that King Xuan may just blindly follow these actions and policies, perhaps with a feeling of reluctance, without the motive of ren-yi. However, since the problem that I am concerned with here is how Mengzi can prevent people from using $l i$ to justify their actions when these actions are truly driven by ren-yi, I will leave problems associated with how Mengzi will find out and evaluate King Xuan's true motive aside and just focus on what would happen if King Xuan did act out of ren-yi.
} 
his moral actions and the realization of his desired $l i$ and use the latter to justify the former. ${ }^{22}$

Finally, will King Xuan use what a virtuous person regards as $l i$ to justify his moral actions? Well, the preliminary requirement for King Xuan to do this is to fully embrace this consequence, which in turn requires him to realize that the $l i$ he has originally desired are inadequate and need to be rectified. If the king could accomplish these, it would suggest that he had moved forward along the moral process, perhaps to a level more or less equivalent to Mengzi. Not only does this moral development have to be achieved through constantly focusing on the heart-mind of ren-yi, but King Xuan, now as a virtuous agent, should be able to reason in the same way as Mengzi, who will take a moral action as right in itself and will not justify it by $l i$. Eventually, when the king looks back, he will realize that:

Although I am [at the beginning] urged to choose the Way because of its consequences in greater satisfaction, the consummation of my choosing is that I shall come to value the Way as good in itself, and shall do this so completely that accepting, cherishing, and acting according to the Way become a part of myself (Nivison, 1996, 209). ${ }^{23}$

In this way, the problem of using $l i$ to justify $y i$ can be naturally avoided.

\section{Conclusion}

Mengzi does not deny that moral actions driven by $y i$ can sometimes generate $l i$ as their natural consequences, neither does he oppose the enjoyment of these li. Nevertheless, one cannot proceed from here to claim that Mengzi is therefore a consequentialist who believes that the resulting $l i$ provides the reason for acting from $y i$, for many passages from the Mengzi show that $y i$ has intrinsic and irreducible moral value for being the virtue that designates a human being's character trait. Mengzi emphasizes the $l i$ associated with $y i$ when he talks with immoralists like King Hui and King Xuan because the Mengzian moral cultivation notes that people at different stages of moral cultivation will develop different characters and abilities; for the immoralists who are still at the starting point of the moral progress and feeling reluctant to give up their corrupted way of life and act from yi, Mengzi believes that it is better to encourage them by telling them that $y i$ will be beneficial. However, as these immoralists proceed along the moral path, Mengzi will soon let them realize

\footnotetext{
${ }^{22}$ It is certainly possible that King Xuan at this point may give up on moral cultivation through despair, but moral cultivation is never meant to be an easy or smooth task. It is beyond my concern to examine all the strategies Mengzi develops for moral cultivation that may help solve this problem in one way or another (for some detailed discussions on this topic, see Curzer 2020; Ivanhoe 2002; Wong 2002). However, based on what has been discussed so far, I think we can say that Mengzi could further encourage King Xuan that acting virtuously is still the "only reliable bet" (Hursthouse 1999, 172) that will lead him to safely enjoy at least the appropriate part of his original objects of desires, because if he acts from $l i$, everything will be lost in the end (again, this can be employed as a hope but not as a reason).

23 Nivison takes this as a feature of Xunzi's 荀子 (ca. 310-235 BC) ethics, but I think in regard to this very respect, Mengzi holds the same.
} 
that $y i$ cannot be justified by $l i$ and thus ensure that they will not become morally disjointed.

\section{Declarations}

Competing Interests The author has no competing interests to declare that are relevant to the content of this article.

\section{References}

Bales, E. R. (1971). Act-utilitarianism: Account of right-making characteristics or decision-making procedure? American Philosophical Quarterly, 8(3), 257-265.

Cai, X. 蔡信安. (1987). “Lun Mengzi de daode jueze” 論孟子的道德抉擇 (On the Moral Choice of Mengzi). Taida zhexue pinglun, 10, 135-174.

Chen, D. 陳大齊. (1987). Chen Bainian xiansheng wenji 陳百年先生文集 (The Collective Works of Sir Chen Bainian), vol. 1, Kong Meng Xun xueshuo 孔孟荀學說 (The Doctrines of Kongzi, Mengzi, and Xunzi). Taiwan shangwu yinshuguan.

Confucius: The Analects. 1979. Translated by D. C. Lau. Hong Kong: The Chinese University Press.

Curzer, H. (2020). Stingy King Meets Savvy Sage: Rethinking the Dialog between King Xuan of Qi and Mengzi. Dao: A Journal of Comparative Philosophy, 19(3), 371-389.

Hu, X. (2021). The Relativity of Ren (Humaneness): Re-examining 2A6 and 6A6 of the Mengzi from the Perspective of Self-Introspection in Experience. Asian Studies, 9(1), 181-201.

Huang, J. 黃俊傑. (1991). Mengxue sixiangshi lun (juanyi) 孟學思想史論 (卷一) (On the Intellectual History of Mengzian Studies, Volume 1). Dongda chuban.

Huang, Z. 黃宗羲. (2005). Huang Zongxi quanji 黃宗羲全集 (The Complete Works of Huang Zongxi), vol. 1, Zhexue, jingxue, zhengzhixue 哲學、經學、政治學 (Philosophy, Confucian Classics, and Political Science). Edited by Shen Shanhong and Wu Guang. Zhejiang guji chubanshe.

Hursthouse, R. (1999). On virtue ethics. Oxford University Press.

Im, M. (2011). Mencius as consequentialist. In C. Fraser, D. Robins, \& T. O'Leary (Eds.), Ethics in early China (pp. 41-63). Hong Kong University Press.

Ivanhoe, P. J. (1991). Character consequentialism: An early confucian contribution to contemporary ethical theory. The Journal of Religious Ethics, 19(1), 55-70.

Ivanhoe, P. J. (2002). Confucian self cultivation and Mengzi's notion of extension. In L. Xiusheng \& P. J. Ivanhoe (Eds.), Essays on the moral philosophy of Mengzi (pp. 221-245). Hackett.

Jiao, X. 焦循. (2017). Mengzi zhengyi 孟子正義 (The Authentic Meaning of the Mengzi). Edited by Shen Wenzhuo. Zhonghua shuju.

Li, M. 李明輝. (2018). Rujia yu Kangde 儒家與康德 (Confucianism and Kant). Lianjing chuban.

Mencius. (2003). Translated by D. C. Lau. Revised ed. The Chinese University Press.

Nivison, D. S. (1980). Two roots or one? Proceedings and Addresses of the American Philosophical Association, 53(6), 739-761.

Nivison, D. S. (1996). Xunzi on 'human nature.' In B. W. Van Norden (Ed.), The ways of confucianism: Investigations in Chinese philosophy (pp. 203-213). Open Court.

Van Norden, B. W. (2007). Virtue ethics and consequentialism in early Chinese philosophy. Cambridge University Press.

Van Norden, B. W. (2008). Mengzi: With Selections from Traditional Commentaries. Hackett.

Railton, P. (1984). Alienation, consequentialism, and the demands of morality. Philosophy and Public Affairs, 13(2), 134-171.

Shen, Q. 沈清松. (1992). Chuantong de zaisheng 傳統的再生 (The Revitalization of Tradition). Yeqiang chubanshe.

Shun, K.-L. (1997). Mencius and early Chinese thought. Stanford University Press.

Stocker, M. (1995). The Schizophrenia of modern ethical theories. In S. M. Cahn \& J. G. Haber (Eds.), 20th century ethical theory (pp. 531-540). Prentice Hall. 
Tang, J. 唐君毅. (1986). Tang Junyi quanji 唐君毅全集 (The Complete Works of Tang Junyi), vol. 14, Zhongguo zhexue yuanlun: yuandao pian juanyi 中國哲學原論: 原道篇卷一 (The Original Dissertation on Chinese Philosophy: The Chapter on the Original Way, Volume 1). Taiwan xuesheng shuju.

Wang, Z. 王澤應. (2017). Zhongguo lishi shang de liyi zhi bian yanjiu 中國歷史上的義利之辨㗏究 (The Study on the Distinction between $\mathrm{Yi}$ and $\mathrm{Li}$ in the Chinese History). Huamulan wenhua shiye youxian gongsi.

Wong, D. B. (2002). Reasons and Analogical Reasoning in Mengzi. In L. Xiusheng \& P. J. Ivanhoe (Eds.), Essays on the Moral Philosophy of Mengzi (pp. 187-220). Hackett.

Yang, H. 楊海文. (1996). “Luelun Mengzi de yili zhi bian yu defu yizhi”略論孟子的義利之辨與德福 一致 (A Short Discussion on Mengzi's Distinction between Optimal Appropriateness and Benefit and the Coherence of Morality and Happiness). Zhongguo zhexueshi (Z1), 102-107.

Ye, R. 葉仁昌. (2011). "Mengzi zhengzhi sixiang zhong yili zhi bian de fenxi: Sizhong zhuyao leixing de tantao”孟子政治思想中義利之辨的分析: 四種主要類型的探討 (The Distinction between Optimal Appropriateness and Benefit in Mengzi’s Political Thought: A Discussion on Four Main Types). Zhengzhi Zhexue Luncong, 50, 1-36.

Zhao, Q. 趙岐 \& Sun, S. 孫萧. (1999). Mengzi zhushu 孟子註疏 (The Annotation and Exegesis of the Mengzi), vol. 11 of Shisanjing zhushu 十三經註疏 (The Annotation of the Thirteen Classics). Edited by Li Xueqin. Beijing daxue chubanshe.

Zhu, X. 朱喜. (1986). Zhuzi yulei 朱子語類 (The Collected Conversations of Master Zhu), 8 vols. Edited by Li Jingde. Zhonghua shuju.

Zhu, X 朱喜. (2002). Zhuzi quanshu 朱子全書 (The Complete Works of Master Zhu), 27 vols. Edited by Zhu Jieren, Yan Zuozhi and Liu Yongxiang. Shanghai guji chubanshe.

Zhu, X. 朱喜. (2011). Sishu zhangju jizhu 四書章句集註 (The Collected Annotations of the Four Books). Zhonghua shuju. 